\title{
Effect of Metformin on Different Non-Diabetes Related Conditions, a Special Focus on Malignant Conditions: Review of Literature
}

\author{
Elamin Abdelgadir ${ }^{\mathrm{a}, \mathrm{b}}$, Razan Ali ${ }^{\mathrm{a}}$, Fauzia Rashid ${ }^{\mathrm{a}}$, Alaaeldin Bashier ${ }^{\mathrm{a}}$
}

\begin{abstract}
Metformin has been proven to be one of the most safe and effective antihyperglycemic agents. Through more than six decades of metformin use, it became the most studied hypoglycemic agent; through these studies, it showed a marvelous non-glycemic related effect. These effects include modulation of different points of cancer timeline, weight reduction, cardiovascular health, thyroid diseases, polycystic ovaries disease and many other medical conditions. The aim of this review was to assess the effect of metformin on non-diabetes related medical diseases. We have examined the studies published in PubMed and summarized different randomized controlled trials, observational trials and review articles. This review has summarized most of the non-glycemic effects of metformin. Metformin has been solidly shown to be effective in weight control with certain medications, effective in neuroprotection, in endothelial health, in control of anti-HIV agent side effects and many other crucial health jeopardies. The effects in cancer timeline modulation have taken the biggest part, since it was the most studied area outside the diabetes field. Having mentioned all the above privileges, and in addition to the robust evidence in glycemic control, this consolidates the position of metformin as a first line agent in treatment of diabetes and pre-diabetes. Perhaps in the near future, we may see other indications to use metformin in non-diabetes patients.
\end{abstract}

Keywords: Metformin; Cancer; Neoplasms; Non-diabetes; Cardiovascular diseases

\section{Introduction}

Metformin is one of the most commonly used diabetes treating agents [1]. It has proved to be very effective, with a wide spectrum of efficacy, safety, as well as being an agent that works at different spots in diabetes pathogenesis paradigm

Manuscript accepted for publication January 17, 2017

aDubai Hospital, Dubai Health Authority, Dubai, UAE

${ }^{\mathrm{b}}$ Corresponding Author: Elamin Abdelgadir, Dubai Hospital, Dubai Health Authority, Dubai, UAE. Email: alaminibrahim@hotmail.com

doi: https://doi.org/10.14740/jocmr2922e
[1]. Metformin is now being used for over 60 years in many parts of the world. During these six decades, plenty of data showed beneficial effects of metformin apart from diabetes. Many diabetes associated conditions, like polycystic ovary disease and fatty liver disease, showed remarkable improvement upon using metformin $[2,3]$. Data showed a protective effect of metformin in reducing cardiovascular complications, not only in diabetes patients but even those with a prediabetes state on the long term [4-6]. Moreover, metformin showed a beneficial effect in some studies in reducing the prevalence of different malignant conditions, and it helped in treating some of them when concomitantly used with other agents. From an endocrine perspective, some studies pointed towards the effect of the metformin on the thyroid function test, even in euthyroid patients. Nonetheless, metformin reduced the size of the thyroid nodule in some small papers in the literature.

In this review, we shall highlight the systemic effects of metformin. We will focus mainly on the non-diabetes-related effects. Reviewed literature included randomized controlled trials, observational trials, and review articles. We have reviewed papers with the primary objective of assessing the nondiabetes related health issues.

We have classified the results according to the area of metformin effect. These areas included the effect on inflammation modulation, weight reduction, and thyroid diseases and so on. In the cancer section, since it is the most studied area with metformin after diabetes, we have subdivided it according to the type of cancer that has been studied to make it easier to assess. Short elaboration will precede all this on the proposed mechanisms of action of metformin molecule.

\section{Mechanism of Action of Metformin}

The metformin molecule works in the humans' bodies at the level of the liver and peripheral tissues, basically, by downsizing the glucose output from the liver, as well as by enhancing the utilization at the peripheral tissues (muscles). This process takes place through the activation of adenosine monophosphate-activated protein kinase (AMPK). The AMPK is the cell regulatory pathway that reduces the energy expenditure at the cellular level. In humans, AMPK is essential for the metabolism of glucose and fatty acids, through reduction of the gluconeogenesis and fatty acids synthesis in the liver, and enhancing glucose uptake, and the fatty acids oxidation by peripheral tis- 
sues [1]. Moreover, mitochondrial metabolism has also been found to be down-regulated by the metformin, which helps in the less gluconeogenesis, and perhaps in, the unexpectedly discovered, tumor modulation privilege of metformin $[7,8]$. Recently, a new pathway has been described to play a role in the anti-neoplastic effect of metformin; metformin was found to modulate adenosine A1 receptor (ADORA1) expression in human colorectal cancer cells [9]. ADORA1 receptors are essential in the cellular energy supply. Thus cancer cells will be energy deprived in case of down-regulation of those receptors. Though the AMPK primarily activates ADORA1, it is considered an entirely different pathway that reduces the number of the colorectal neoplastic cells and induces the apoptosis [9]. Further organ-specific pathways will be discussed in the article below.

\section{Metformin as an anti-inflammatory agent}

It has been hypothesized that inhibition of the NF-kB by metformin down-regulates the inflammatory response; this might be the key answer to the reduction in the cardiovascular events [10]. However, other studies have challenged this hypothesis by demonstrating minimal [11], or no influence on the inflammatory response [12].

\section{Metformin as an anti-oxidant}

This privilege is still to be explained by scientists. The hypotheses include lowering the reactive oxygen species, upregulation of uncoupled protein 2 in the fat cells, as well as the AMPK system activation $[1,8,13]$. This as mentioned above reduces gluconeogenesis, and increase fatty acids metabolism, as well as B-oxidation in the fat tissues.

\section{Metformin improves endothelial function}

There is substantial evidence that links dysglycemia with an unfavorable endothelial health, increasing the risk of thrombus formation [12]. The mechanism of this is still controversial; endothelial function modulation was suggested to be directly from the metformin molecule $[14,15]$ or via insulin resistance improvement, or at most extreme, no endothelial benefits at all [15].

\section{Metformin as a weight reducing agent}

Metformin is not a weight reducing agent on its own; many researchers have concluded that metformin might halt the weight gain caused by other diabetes or diabetes-related medications like insulin, thiazolidinedione, sulfonylureas, antipsychotics, etc. [16-19].

The mechanism behind weight reduction is well established. The weight changes are more prominent in patients with impaired glucose tolerance [20], unlike, obese people who do not have diabetes in whom metformin failed to reduce weight [21].

Many reports have elaborated on the mechanistic explanation of metformin and weight loss, which has been attributed to modest reduction in the carbohydrates uptake in the gut as well as the modulation of the vicious cycle of the insulin resistance, and reduction in leptin levels, in addition to the augmentation of the glucagon-like peptide- 1 effects on fat cells [22-24].

\section{Metformin and the thyroid gland}

Unlike type 1 diabetes, there is no clear association between T2DM and the thyroid illnesses. But the treatment (specifically metformin) might have some implications on the status of the thyroid function parameters. In the last decade, many reports have highlighted the possibility of metformin affecting the thyroid-stimulating hormone (TSH) and concluded that it has no effect on thyroid hormone (T3 and T4) [25, 26].

In a recent study, Cappelli et al have demonstrated a statistically significant difference in the level of the TSH $(\mathrm{P}<$ $0.05)$, in diabetic patients who were started on metformin, while the level of T4 and T3 remained unchanged over 1 year. The change took place in the group with an already existing hypothyroidism whether they are on treatment or not, while the euthyroid group had their TSH unchanged. Therefore, the authors recommended that TSH needs to be checked in patients with T2DM even without a concomitant hypothyroidism [27]. An interesting study from Malta evaluated the effect of the metformin on the TSH and T4. The study included 238 individual with type 2 diabetes (121 males and 117 females); nearly half of them were on metformin. They have excluded those with history of thyroid illness, recent major illness, and those who are receiving active thyroid treatment. TSH was numerically lower in metformin-treated patients, without reflecting statistical significance. The T4 was higher in the females who were on metformin compared to the control group $(18.4$ vs. $16.5 \mathrm{pmol} / \mathrm{L})(\mathrm{P}<0.01)$. They concluded that the metformin is likely affecting the thyroid function through inhibition of the peripheral conversion of thyroxine to triiodothyronine [28].

\section{Metformin and the nervous system}

The role of metformin in the nervous system is uniquely interesting. We know now that modulation of diabetes reduces all cardiovascular mortalities [5-7]. Out of the context of diabetes mellitus and the related vascular insults, metformin was thought to play a minor role in Alzheimer's disease, the disease that used to be unofficially labeled as type 3 diabetes. In Alzheimer's disease, there is remarkable progressive insulin resistance of the brain cells, leading to formation and accumulation of the amyloid cells (due to lack of insulin effect on the cells) after a sequence of chemical transformations [29, 30].

The role of metformin in those cascades is not clear. But it is quite known that brain cells are dependent on the glucose 
for survival, as well as the high probability of oxidative injuries since they have low antioxidant enzymes content and frequent exposure to oxidative stresses [31, 32]. Moreover, activation of the AMPK pathway is thought to play a role in reducing the insulin resistance and the oxidative stress. And, as mentioned earlier, metformin was found to accelerate the activation of the AMPK $[1,31]$. Activation of AMPK by metformin could partly help in understanding the minor protective role of metformin in Alzheimer's disease. Moreover, AMPK is also expected to play a cardinal role in the pathophysiology of other various neurological diseases like Parkinson's disease, and amyotrophic lateral sclerosis.

Another way of oxidative stress augmentation is the mitochondrial metabolism dysfunction. There is a protein called permeability transition protein; this protein is responsible for the programmed cell death (apoptosis). When the permeability transition protein is released, it stimulates the production of the cellular apoptotic proteins, which result later in the cell death. Metformin was found to play a pivotal role in this cascade. Metformin breaks the cycle of the permeability transition pore in the mitochondria, as well as induces the production of the cytochrome-c. Both effects of metformin in the mitochondria delay the programmed cell death $[32,33]$.

\section{Metformin and the blood homeostasis}

It was mentioned earlier that metformin reduces the incidence of cardiovascular events in diabetes patients. This takes place through various cascades (glycemia and non-glycemia related cascades). Metformin, in high doses, was shown to various coagulation factors in humans. Metformin reduces the systemic production of the tissue type plasminogen activator, Von Willibrand factor, and plasminogen activator inhibitor [34]. In addition to that, metformin was found to modulate the fibrin threads formation; this takes place by reducing the factor XIII functions and structural modeling of the fibrin threads [12]. Nonetheless, metformin was found to reduce the levels of plasminogen activator inhibitor-1, and Von Willibrand factor from the unhealthy endothelium in patients with no underlying diabetes mellitus [35].

\section{Metformin and HIV treatment-related side effects}

It is known that antiretroviral agents (HIV treatment) lead to devastating fats and other metabolic consequences such as insulin resistance, dyslipidemia, worsening of the blood glucose levels, and lipodystrophy [36]. Those side effects might take place in as high as $80 \%$ of the anti-retroviral therapy treated patients [36]. Strenuous exercise and dietary modification reduce the morphological as well as the chemical consequences of the antiretroviral agents. Moreover, metformin, when added to the lifestyle modification tools, can effectively prevent those consequences, but the effect was confined basically to an improvement of visceral fat distribution [37, 38]. Nonetheless, metformin with antiretroviral agents was found to be efficiently reducing the risk of insulin insensitivity, hyperglyce- mia, weight gain, dyslipidemia, as well as improvement in the flow-mediated vascular dilatation [37-39].

\section{Metformin and Cancers}

\section{Metformin and liver cancer}

An interesting meta-analysis from China, which looked at all the trials that assessed liver cancer risk modulation with metformin, the authors have looked into five trials out of the PubMed and SciVerse Scopus databases. The total number of patients studied was approximately 105,495 . In this metaanalysis, they concluded that metformin appears to play a role in the reduction of liver cancer risk in type 2 diabetes patients. The authors have called for further mechanistic, well-designed trials to consolidate this conclusion [40].

\section{Metformin and pancreatic cancer}

Many studies have evaluated this point, having the possible link between diabetes and pancreatic cancer. For instance, in a meta-analysis from Australia, Huxley, and his colleagues assessed the computer-based literature from 1966 to 2005. The researchers have found a hint to a causal relationship between type 2 diabetes and pancreatic cancer. An interesting finding in this study is that those who had a shorter duration of diabetes had a higher risk of pancreatic cancer development [41].

Another study has looked into the patients who were going for surgery for pancreatic cancer. They have found a statistically significant lower risk of mortality in patients with pancreatic cancer if they were on metformin. The authors called for further studies to know more about the anti-tumorigenic privilege of metformin in this context [42].

\section{Metformin and breast cancer}

As already mentioned in this article, the principal mechanism of action of metformin is by exerting a direct effect on AMPK; this occurs when metformin lowers the ATP ratio in cells causing energetic stress and thus stimulating the AMPK pathway responsible for energy homeostasis. Excess energy, in turn, will signal the need to decrease the energy consumption and thus switch off cell growth and proliferation causing the desired cytotoxic effect on breast cells. Besides, metformin exerts an indirect effect on cells by lowering the insulin levels, which decreases the levels of P13k pathway and thus inhibit cell growth and proliferation [43]. Metformin reported a better pathologic complete response rate when taken regardless if the patient had diabetes or not [44]. In another laboratory study, metformin was tested at different breast cancer differentiation phases; it showed inhibitory signals at early stages of cell differentiation of breast cancer [45]. It is worth mentioning that higher doses of metformin are needed to attain the antineoplastic effect $(1.5-2.25 \mathrm{~g})$, though this point needs further longterm data to support it [46]. 


\section{Metformin and colorectal cancer}

A meta-analysis of five studies including 108,161 diabetic patients indicated a notable lower risk of colorectal carcinoma in those treated with metformin [47]. Also, an updated meta-analysis of studies reviewed up until 2015 augmented metformin's ability in lowering the risk of colorectal cancer and in improving the survival outcome in such patients [48]. Another recent systemic review and meta-analysis reported metformin superiority in lowering the risk of colorectal cancer as compared to other anti-diabetic modalities [49, 50]. Lee et al (2012) looked into 595 patients with colorectal cancer, and those on metformin had a lower risk of overall and cancer-related mortality $(\mathrm{P}=$ 0.15 and 0.37 , respectively) [51].

\section{Metformin and prostate cancer}

There is an ongoing debate between the use of metformin and the risk of prostate carcinoma. Many meta-analyses and studies are done. However, only a few showed the positive association of prostate cancer with metformin, while others appreciated metformin's effect in reducing the risk of developing prostate cancer [52]. Another debate is about the use of metformin and the outcome in patients with prostate cancer. Metformin improved the outcome of prostate cancer and overall mortality, as supported by many studies for the benefits of metformin as an adjuvant therapy for prostate cancer [53], like it did in many other earlier mentioned malignancies. However, two meta-analysis and studies are suggesting no proven benefits of what is expected by metformin on cancer cells [54-57].

\section{Metformin and lung cancer}

Sakoda et al in a cohort study showed no association between metformin use and risk of lung cancer regardless how long patients were on metformin or the maximum dose used. However, this finding applied to diabetic patients who were 40 years and older and did not include other factors like smoking for example [58]. Furthermore, similar evidence is found in literature such as the case-control analysis by Bodmer et al where they showed a neutral effect of metformin, favorable effect of sulphonylureas and higher incidences with insulin use [59]. Smiechowski et al included 115,293 oral hypoglycemics agent (OHA) users from the United Kingdom General Practice Research Database between 1988 and 2009, with 1,061 patients diagnosed with lung cancer during follow-up (rate 2.0/1,000 person-years). Metformin was not absolutely neutral in the cancer outcome, and they concluded that the results in other observational trials were biased in methodology and selection [60].

Looking from a different view, a retrospective cohort study by Wink et al concluded that diabetic patients on metformin diagnosed with locally advanced non-small cell lung cancer had a less chance of disease progression and metastasis when received concurrent chemo-radiotherapy and metformin than those who were not on metformin [61]. However, another meta-analysis including 17 studies showed metformin had no survival ben- efit when used as an adjuvant with chemo-radiotherapy while it conferred a better survival outcome to lung cancer patients including those on chemotherapy only [62]. These results were replicated in Menamin et al's study, which assessed lung cancer patient registry between 1998 and 2009, and they found a weak favorable outcome when metformin was on board before or after diagnosis [63]. Interestingly, in the same study, there was a weak negative impact on other hypoglycemic agents like sulphonylureas and thiazolidinedione [63]. Further prospective studies are needed since the data in this perspective are contradicting.

\section{Metformin and thyroid cancer}

Klubo-Gwiezdzinska et al published findings of metformin's anti-proliferative effects on differentiated thyroid cancers when they examined 34 patients with differentiated thyroid cancer (DTC) taking metformin versus 21 non-metformin using patients, tumor size was smaller, and progression was slower in the metformin group [64]. One of the theories in DTC response to metformin is the $\mathrm{p} 70 \mathrm{~S} 6 \mathrm{~K} / \mathrm{pS} 6$ pathway that induces the cancer cell metabolic stress and the autophagy later [64]. Similar experimental findings by Klubo-Gwiezdzinska et al on medullary thyroid cancer (MTC) cells found slowness of cellular progression in metformin-treated patients. They stated that cyclin D1 (usually overexpressed in cancer cells) was remarkably inhibited, through inhibition of $\mathrm{mTOR} / \mathrm{p} 70 \mathrm{~S} 6 \mathrm{~K} /$ pS6 signaling and down-regulation of pERK. Out of this sophisticated process, they concluded metformin could have a potential additional role in treating MTC [65], therefore, adding thyroid cancer to the list of cancers showing a decreased cancer-specific mortality with the use of metformin.

\section{Metformin and endometrial cancer}

A 5-year retrospective analysis of metformin use with endometrial cancer showed a good outcome on the overall survival. However, data were not confined to non-diabetics only but included those diabetic patients who were kept on metformin, thus the results may be due to an improvement in all-cause mortality rather than being cancer-specific. Metformin's role in endometrial cancer recurrence remains unclear [66].

A recent study in 2016 explained the improvement of overall survival in patients with advanced endometrial cancer, undergoing chemotherapy while taking metformin. However, the drawback of the study was the end point as it was death due to any cause, not specifically due to the endometrium cancer [67]. Thus many studies have pointed towards the improvement in survival might be because of the patient's overall health improvement rather than the regression/resolution of endometrial cancer per se [68-70].

A prospective study on newly diagnosed endometrial cancer patients demonstrated the reduction in relevant serum and molecular markers by metformin in 7 or more days only. However, only 20 patients continued the trial, which calls for further elaboration on metformin's benefits by using a bigger sample size [68]. 
Another point that has not been described yet in the previously mentioned mechanisms of metformin on tumor cells is the FOXO1 pathway involvement. Zou et al found a new path that can be the start for further therapeutic agents in preventing endometrial cancer. It was depicted by the following: giving an AMPK inhibitor which in turn inhibited the FOXO1 pathway indicating the relationship between both the pathways and by injecting a silencing RNA for FOXO1 in endometrial cells which subsequently eradicated metformin's anti-proliferative effect.

In short, many studies promise the beneficial effect of metformin on endometrium cancer including progesteroneresistant cancer cells [71].

\section{Metformin and cervical cancer}

Very limited data are available about metformin on cervical cancer suppression as most of the retrospective studies were confined to diabetics who were on metformin already.

However, one study by Xiao et al examined metformin's dynamics in cervical cancer cells and focused on the activity of LKB1 in these cells. The cell lines responsive to metformin were found to stimulate AMPK via LKB1 and prevent mTOR; in contrary, the non-responsive cells to metformin were those who were void of LKB1. Also, the writers detected that metformin was able to repress certain cervical cancer cell lines (such as those containing C33A, ME180 and CaSki) while being less effective against other cell lines (such as HeLa, HT-3 and MS751).

These outcomes indicated that metformin could have an adjuvant role in treating cervical cancer, especially in tumor cells containing LKB1 [72].

\section{Metformin and renal cell cancer}

A published article in 2013 by Liu et al showed metformin requires a specific dose and times to be effective in preventing renal cell carcinoma (RCC). Another crucial step was its ability to activate the AMPK pathway that subsequently leads to inhibition of mTOR that is responsible for cell growth. Metformin also inhibited mTOR independently of AMPK, therefore making it more effective in wiping out the malignant cell growth. Finally, the article also discussed its additional antiproliferative effect on RCCs by suppressing cyclin D gene which is responsible for cell growth [73].

In 2014, Yang et al revealed that metformin is also able to prevent RCC by regulation of the gene miR-26a, which will thereby inhibit cyclin D1 expression (responsible for cell growth) and up-regulate PTEN expression (a tumor suppressor gene) [75]. But on the clinical ground, metformin showed no association in preventing recurrence of RCC after its resection; however, future further studies are required [75].

\section{Metformin and melanoma}

An article in 2011 by Tomic et al entertained an additional anti- proliferative effect of metformin in addition to AMPK activation. The activation of the AMPK ends cell proliferation, and subsequently, apoptosis develops within $96 \mathrm{~h}$. Interestingly this article illustrated two findings: one is how metformin leads to phagocytosis of cells containing AMPK, which are malignantly mutated, whilst sparing the healthy cells containing AMPK. Secondly, metformin can reduce proliferation of tumor cells effectively in an AMPK-independent manner as well [76]. Further on in 2013, an update to this article showed metformin's anti-metastatic effects on aggressive malignancies like melanomas [77].

\section{Conclusion}

Metformin is one of the most widely prescribed antihyperglycemic agents. It is irreplaceable as first line hypoglycemic agent since decades, despite the development of numerous new hypoglycemic drugs due to its unique effect on glycemic control by addressing the insulin resistance. Being one of the older drugs in the field time has witnessed its good extra glycemic effects and it is worth doing some well-designed casecontrol studies and randomized controlled trials to confirm these benefits.

\section{References}

1. Kahn BB, Alquier T, Carling D, Hardie DG. AMP-activated protein kinase: ancient energy gauge provides clues to modern understanding of metabolism. Cell Metab. 2005;1(1):15-25.

2. Rashid M, Roberts EA. Nonalcoholic steatohepatitis in children. J Pediatr Gastroenterol Nutr. 2000;30(1):48-53.

3. Reinehr T, Kiess W, Kapellen T, Andler W. Insulin sensitivity among obese children and adolescents, according to degree of weight loss. Pediatrics. 2004;114(6):15691573.

4. Kannel WB, McGee DL. Diabetes and glucose tolerance as risk factors for cardiovascular disease: the Framingham study. Diabetes Care. 1979;2(2):120-126.

5. Wingard DL, Barrett-Connor E. NationalDiabetes Data Group. Diabetes in America. Heart disease and diabetes. 1995, Washington, D.C: GPO, 429-48. NIH publication no. $95-1468,2$.

6. Johnson JA, Majumdar SR, Simpson SH, Toth EL. Decreased mortality associated with the use of metformin compared with sulfonylurea monotherapy in type 2 diabetes. Diabetes Care. 2002;25(12):2244-2248.

7. Shaw RJ, Lamia KA, Vasquez D, Koo SH, Bardeesy N, Depinho RA, Montminy M, et al. The kinase LKB1 mediates glucose homeostasis in liver and therapeutic effects of metformin. Science. 2005;310(5754):1642-1646.

8. Faure P, Rossini E, Wiernsperger N, Richard MJ, Favier A, Halimi S. An insulin sensitizer improves the free radical defense system potential and insulin sensitivity in high fructose-fed rats. Diabetes. 1999;48(2):353-357.

9. Lan B, Zhang J, Zhang P, Zhang W, Yang S, Lu D, Li $\mathrm{W}$, et al. Metformin suppresses CRC growth by induc- 
ing apoptosis via ADORA1. Front Biosci (Landmark Ed). 2017;22:248-257.

10. Isoda K, Young JL, Zirlik A, MacFarlane LA, Tsuboi N, Gerdes N, Schonbeck U, et al. Metformin inhibits proinflammatory responses and nuclear factor-kappaB in human vascular wall cells. Arterioscler Thromb Vasc Biol. 2006;26(3):611-617.

11. Haffner S, Temprosa M, Crandall J, Fowler S, Goldberg $\mathrm{R}$, Horton E, Marcovina S, et al. Intensive lifestyle intervention or metformin on inflammation and coagulation in participants with impaired glucose tolerance. Diabetes. 2005;54(5):1566-1572.

12. De Jager J, Kooy A, Lehert P, Bets D, Wulffele MG, Teerlink T, Scheffer PG, et al. Effects of short-term treatment with metformin on markers of endothelial function and inflammatory activity in type 2 diabetes mellitus: a randomized, placebo-controlled trial. J Intern Med. 2005;257(1):100-109.

13. Anedda A, Rial E, Gonzalez-Barroso MM. Metformin induces oxidative stress in white adipocytes and raises uncoupling protein 2 levels. J Endocrinol. 2008;199(1):3340.

14. Mather KJ, Verma S, Anderson TJ. Improved endothelial function with metformin in type 2 diabetes mellitus. J Am Coll Cardiol. 2001;37(5):1344-1350.

15. Vitale C, Mercuro G, Cornoldi A, Fini M, Volterrani M, Rosano GM. Metformin improves endothelial function in patients with metabolic syndrome. J Intern Med. 2005;258(3):250-256.

16. Effect of intensive blood-glucose control with metformin on complications in overweight patients with type 2 diabetes (UKPDS 34). UK Prospective Diabetes Study (UKPDS) Group. Lancet. 1998;352(9131):854-865.

17. Kahn SE, Haffner SM, Heise MA, Herman WH, Holman RR, Jones NP, Kravitz BG, et al. Glycemic durability of rosiglitazone, metformin, or glyburide monotherapy. N Engl J Med. 2006;355(23):2427-2443.

18. Lund SS, Tarnow L, Frandsen M, Nielsen BB, Hansen $\mathrm{BV}$, Pedersen $\mathrm{O}$, Parving $\mathrm{HH}$, et al. Combining insulin with metformin or an insulin secretagogue in non-obese patients with type 2 diabetes: 12 month, randomised, double blind trial. BMJ. 2009;339:b4324.

19. Wu RR, Zhao JP, Jin H, Shao P, Fang MS, Guo XF, He $Y Q$, et al. Lifestyle intervention and metformin for treatment of antipsychotic-induced weight gain: a randomized controlled trial. JAMA. 2008;299(2):185-193.

20. Lily M, Godwin M. Treating prediabetes with metformin: systematic review and meta-analysis. Can Fam Physician. 2009;55(4):363-369.

21. Desilets AR, Dhakal-Karki S, Dunican KC. Role of metformin for weight management in patients without type 2 diabetes. Ann Pharmacother. 2008;42(6):817-826.

22. Glueck CJ, Fontaine RN, Wang P, Subbiah MT, Weber K, Illig E, Streicher P, et al. Metformin reduces weight, centripetal obesity, insulin, leptin, and low-density lipoprotein cholesterol in nondiabetic, morbidly obese subjects with body mass index greater than 30. Metabolism. 2001;50(7):856-861.

23. Kusaka I, Nagasaka S, Horie H, Ishibashi S. Met- formin, but not pioglitazone, decreases postchallenge plasma ghrelin levels in type 2 diabetic patients: a possible role in weight stability? Diabetes Obes Metab. 2008;10(11):1039-1046.

24. Mannucci E, Ognibene A, Cremasco F, Bardini G, Mencucci A, Pierazzuoli E, Ciani S, et al. Effect of metformin on glucagon-like peptide 1 (GLP-1) and leptin levels in obese nondiabetic subjects. Diabetes Care. 2001;24(3):489-494.

25. Vigersky RA, Filmore-Nassar A, Glass AR. Thyrotropin suppression by metformin. J Clin Endocrinol Metab. 2006;91(1):225-227.

26. Isidro ML, Penin MA, Nemina R, Cordido F. Metformin reduces thyrotropin levels in obese, diabetic women with primary hypothyroidism on thyroxine replacement therapy. Endocrine. 2007;32(1):79-82.

27. Cappelli C, Rotondi M, Pirola I, Agosti B, Gandossi E, Valentini U, De Martino E, et al. TSH-lowering effect of metformin in type 2 diabetic patients: differences between euthyroid, untreated hypothyroid, and euthyroid on L-T4 therapy patients. Diabetes Care. 2009;32(9):15891590.

28. Vella S, Cachia MJ, Vassallo J. The effects of metformin on thyroid function. Poster presentation at the spring meeting of the Scottish Society for Experimental Medicine (Aberdeen, 29th May, 2009).

29. Spasic MR, Callaerts P, Norga KK. AMP-activated protein kinase (AMPK) molecular crossroad for metabolic control and survival of neurons. Neuroscientist. 2009;15(4):309-316.

30. Culmsee C, Monnig J, Kemp BE, Mattson MP. AMPactivated protein kinase is highly expressed in neurons in the developing rat brain and promotes neuronal survival following glucose deprivation. J Mol Neurosci. 2001;17(1):45-58.

31. Santomauro Junior AC, Ugolini MR, Santomauro AT, Souto RP. [Metformin and AMPK: an old drug and a new enzyme in the context of metabolic syndrome]. Arq Bras Endocrinol Metabol. 2008;52(1):120-125.

32. Kroemer G, Reed JC. Mitochondrial control of cell death. Nat Med. 2000;6(5):513-519.

33. van der Heide LP, Ramakers GM, Smidt MP. Insulin signaling in the central nervous system: learning to survive. Prog Neurobiol. 2006;79(4):205-221.

34. Grant PJ. Beneficial effects of metformin on haemostasis and vascular function in man. Diabetes Metab. 2003;29(4 Pt 2):6S44-52.

35. Charles MA, Morange P, Eschwege E, Andre P, Vague P, Juhan-Vague I. Effect of weight change and metformin on fibrinolysis and the von Willebrand factor in obese nondiabetic subjects: the BIGPRO1 Study. Biguanides and the Prevention of the Risk of Obesity. Diabetes Care. 1998;21(11):1967-1972.

36. Kinlaw WB, Marsh B. Adiponectin and HIV-lipodystrophy: taking HAART. Endocrinology. 2004;145(2):484486.

37. Hadigan C, Corcoran C, Basgoz N, Davis B, Sax P, Grinspoon S. Metformin in the treatment of HIV lipodystrophy syndrome: A randomized controlled trial. JAMA. 
2000;284(4):472-477.

38. Sheth SH, Larson RJ. The efficacy and safety of insulinsensitizing drugs in HIV-associated lipodystrophy syndrome: a meta-analysis of randomized trials. BMC Infect Dis. 2010;10:183.

39. Fu Y, Zhang XN, Li Y, Xiang P, Xu SH. [Discoid medial meniscus of double knees: a case report and literature review]. Zhongguo Gu Shang. 2016;29(2):135-137.

40. Zhang ZJ, Zheng ZJ, Shi R, Su Q, Jiang Q, Kip KE. Metformin for liver cancer prevention in patients with type 2 diabetes: a systematic review and meta-analysis. J Clin Endocrinol Metab. 2012;97(7):2347-2353.

41. Huxley R, Ansary-Moghaddam A, Berrington de Gonzalez A, Barzi F, Woodward M. Type-II diabetes and pancreatic cancer: a meta-analysis of 36 studies. $\mathrm{Br} \mathrm{J}$ Cancer. 2005;92(11):2076-2083.

42. Cerullo M, Gani F, Chen SY, Canner J, Pawlik TM. Metformin Use Is Associated with Improved Survival in Patients Undergoing Resection for Pancreatic Cancer. J Gastrointest Surg. 2016;20(9):1572-1580.

43. Camacho L, Dasgupta A, Jiralerspong S. Metformin in breast cancer - an evolving mystery. Breast Cancer Res. 2015;17:88.

44. Jiralerspong S, Palla SL, Giordano SH, Meric-Bernstam F, Liedtke C, Barnett CM, Hsu L, et al. Metformin and pathologic complete responses to neoadjuvant chemotherapy in diabetic patients with breast cancer. J Clin Oncol. 2009;27(20):3297-3302.

45. Hadad SM, Hardie DG, Appleyard V, Thompson AM. Effects of metformin on breast cancer cell proliferation, the AMPK pathway and the cell cycle. Clin Transl Oncol. 2014;16(8):746-752.

46. Iliopoulos D, Hirsch HA, Struhl K. Metformin decreases the dose of chemotherapy for prolonging tumor remission in mouse xenografts involving multiple cancer cell types. Cancer Res. 2011;71(9):3196-3201.

47. Zhang ZJ, Zheng ZJ, Kan H, Song Y, Cui W, Zhao G, Kip KE. Reduced risk of colorectal cancer with metformin therapy in patients with type 2 diabetes: a meta-analysis. Diabetes Care. 2011;34(10):2323-2328.

48. He XK, Su TT, Si JM, Sun LM. Metformin Is Associated With Slightly Reduced Risk of Colorectal Cancer and Moderate Survival Benefits in Diabetes Mellitus: A Meta-Analysis. Medicine (Baltimore). 2016;95(7):e2749.

49. Singh S, Singh H, Singh PP, Murad MH, Limburg PJ. Antidiabetic medications and the risk of colorectal cancer in patients with diabetes mellitus: a systematic review and meta-analysis. Cancer Epidemiol Biomarkers Prev. 2013;22(12):2258-2268.

50. Ramjeesingh R, Orr C, Bricks CS, Hopman WM, Ham$\operatorname{mad} \mathrm{N}$. A retrospective study on the role of diabetes and metformin in colorectal cancer disease survival. Curr Oncol. 2016;23(2):e116-122.

51. Lee JH, Jeon SM, Hong SP, Cheon JH, Kim TI, Kim WH. Metformin use is associated with a decreased incidence of colorectal adenomas in diabetic patients with previous colorectal cancer. Dig Liver Dis. 2012;44(12):1042-1047.

52. Sayyid RK, Fleshner NE. Potential role for metformin in urologic oncology. Investig Clin Urol. 2016;57(3):157-
164.

53. Yu H, Yin L, Jiang X, Sun X, Wu J, Tian H, Gao X, et al. Effect of metformin on cancer risk and treatment outcome of prostate cancer: a meta-analysis of epidemiological observational studies. PLoS One. 2014;9(12):e116327.

54. Hwang IC, Park SM, Shin D, Ahn HY, Rieken M, Shariat SF. Metformin association with lower prostate cancer recurrence in type 2 diabetes: a systematic review and meta-analysis. Asian Pac J Cancer Prev. 2015;16(2):595600.

55. Raval AD, Thakker D, Vyas A, Salkini M, Madhavan S, Sambamoorthi U. Impact of metformin on clinical outcomes among men with prostate cancer: a systematic review and meta-analysis. Prostate Cancer Prostatic Dis. 2015;18(2):110-121.

56. Stopsack KH, Ziehr DR, Rider JR, Giovannucci EL. Metformin and prostate cancer mortality: a meta-analysis. Cancer Causes Control. 2016;27(1):105-113.

57. Deng D, Yang Y, Tang X, Skrip L, Qiu J, Wang Y, Zhang F. Association between metformin therapy and incidence, recurrence and mortality of prostate cancer: evidence from a meta-analysis. Diabetes Metab Res Rev. 2015;31(6):595-602.

58. Sakoda LC, Ferrara A, Achacoso NS, Peng T, Ehrlich SF, Quesenberry CP, et al. Metformin use and lung cancer risk in patients with diabetes. Cancer Prev Res (Phila). 2015;8(2):174-179.

59. Bodmer M, Becker C, Jick SS, Meier CR. Metformin does not alter the risk of lung cancer: a case-control analysis. Lung Cancer. 2012;78(2):133-137.

60. Smiechowski BB, Azoulay L, Yin H, Pollak MN, Suissa $\mathrm{S}$. The use of metformin and the incidence of lung cancer in patients with type 2 diabetes. Diabetes Care. 2013;36(1):124-129.

61. Wink KC, Belderbos JS, Dieleman EM, Rossi M, Rasch CR, Damhuis RA, Houben RM, et al. Improved progression free survival for patients with diabetes and locally advanced non-small cell lung cancer (NSCLC) using metformin during concurrent chemoradiotherapy. Radiother Oncol. 2016;118(3):453-459.

62. Wan G, Yu X, Chen P, Wang X, Pan D, Li L, Cai X, et al. Metformin therapy associated with survival benefit in lung cancer patients with diabetes. Oncotarget. 2016;7(23):35437-35445.

63. Menamin UC, Cardwell CR, Hughes CM, Murray LM. Metformin use and survival from lung cancer: A population-based cohort study. Lung Cancer. 2016;94:35-39.

64. Klubo-Gwiezdzinska J, Costello J, Jr., Patel A, Bauer A, Jensen K, Mete M, Burman KD, et al. Treatment with metformin is associated with higher remission rate in diabetic patients with thyroid cancer. J Clin Endocrinol Metab. 2013;98(8):3269-3279.

65. Klubo-Gwiezdzinska J, Jensen K, Costello J, Patel A, Hoperia V, Bauer A, Burman KD, et al. Metformin inhibits growth and decreases resistance to anoikis in medullary thyroid cancer cells. Endocr Relat Cancer. 2012;19(3):447-456.

66. Ko EM, Walter P, Jackson A, Clark L, Franasiak J, Bolac C, Havrilesky LJ, et al. Metformin is associated with im- 
proved survival in endometrial cancer. Gynecol Oncol. 2014;132(2):438-442.

67. Ezewuiro O, Grushko TA, Kocherginsky M, Habis M, Hurteau JA, Mills KA, Hunn J, et al. Association of Metformin Use with Outcomes in Advanced Endometrial Cancer Treated with Chemotherapy. PLoS One. 2016;11(1):e0147145.

68. Soliman PT, Zhang Q, Broaddus RR, Westin SN, Iglesias D, Munsell MF, Schmandt R, et al. Prospective evaluation of the molecular effects of metformin on the endometrium in women with newly diagnosed endometrial cancer: A window of opportunity study. Gynecol Oncol. 2016;143(3):466-471.

69. Zou J, Hong L, Luo C, Li Z, Zhu Y, Huang T, Zhang Y, et al. Metformin inhibits estrogen-dependent endometrial cancer cell growth by activating the AMPK-FOXO1 signal pathway. Cancer Sci. 2016;107(12):1806-1817.

70. Seebacher V, Bergmeister B, Grimm C, Koelbl H, Reinthaller A, Polterauer S. The prognostic role of metformin in patients with endometrial cancer: a retrospective study. Eur J Obstet Gynecol Reprod Biol. 2016;203:291-296.

71. Zhuo Z, Wang A, Yu H. Metformin targeting autophagy overcomes progesterone resistance in endometrial carcinoma. Arch Gynecol Obstet. 2016;294(5):1055-1061.
72. Xiao X, He Q, Lu C, Werle KD, Zhao RX, Chen J, Davis $\mathrm{BC}$, et al. Metformin impairs the growth of liver kinase B1-intact cervical cancer cells. Gynecol Oncol. 2012;127(1):249-255.

73. Liu J, Li M, Song B, Jia C, Zhang L, Bai X, Hu W. Metformin inhibits renal cell carcinoma in vitro and in vivo xenograft. Urol Oncol. 2013;31(2):264-270.

74. Yang FQ, Wang JJ, Yan JS, Huang JH, Li W, Che JP, Wang GC, et al. Metformin inhibits cell growth by upregulating microRNA-26a in renal cancer cells. Int J Clin Exp Med. 2014;7(10):3289-3296.

75. Hakimi AA, Chen L, Kim PH, Sjoberg D, Glickman L, Walker MR, Russo P. The impact of metformin use on recurrence and cancer-specific survival in clinically localized high-risk renal cell carcinoma. Can Urol Assoc J. 2013;7(11-12):E687-691.

76. Tomic T, Botton T, Cerezo M, Robert G, Luciano F, Puissant A, Gounon P, et al. Metformin inhibits melanoma development through autophagy and apoptosis mechanisms. Cell Death Dis. 2011;2:e199.

77. Cerezo M, Tichet M, Abbe P, Ohanna M, Lehraiki A, Rouaud F, Allegra M, et al. Metformin blocks melanoma invasion and metastasis development in AMPK/p53-dependent manner. Mol Cancer Ther. 2013;12 